\title{
PERSALINAN DISTOSIA PADA REMAJA DI BAGIAN OBSTETRI- GINEKOLOGI BLU RSUP PROF. DR. R. D. KANDOU MANADO
}

\author{
${ }^{1}$ Judita Paat \\ ${ }^{2}$ Eddy Suparman \\ ${ }^{2}$ Hermie Tendean
}

\author{
${ }^{1}$ Kandidat Skripsi Fakultas Kedokteran Universitas Sam Ratulangi Manado \\ ${ }^{2}$ Bagian Obstetri dan Ginekologi Fakultas Kedokteran Universitas Sam Ratulangi Manado \\ Email: Dithapaat@yahoo.com
}

\begin{abstract}
Labour process depends on 3 factors as follows: power, passanger, and passage. Power consists of contraction of the uterus, abdominal wall muscles, and diaphragm, as well as action of the ligaments. Passanger is the fetus itself and passage is the anatomical structures involved in expulsion of fetus during labour. Adolescent is a transition period with physical, emotional, and psyhological changes. In pregnant women aged less than 20 years, the uterus and pelvis have not fully developed with a consequence of dystocia. This study aimed to obtain the profile of dystocia among adolescent in Prof. Dr. R. D. Kandou Hospital Manado from Januari 2012 to December 2013. This was a descriptive retrospective study. The results showed that most dystocia among adolescent occured in age group $>16$ years, and the most frequent causes were the position of fetus in utero, the fetus itself, and the anatomical passage. The most frequent treatment was sectio caesaria. Dystocia rarely causes severe complications.

Kata kunci: persalinan distosia, remaja
\end{abstract}

\begin{abstract}
Abstrak: Proses persalinan dipengaruhi oleh tiga faktor yaitu: kekuatan mendorong janin keluar (power) yang meliputi his (kekuatan uterus), kontraksi otot dinding perut, kontraksi diafragma dan ligamentum action. Faktor lainnya ialah faktor janin (passanger) dan faktor jalan lahir (passage). Masa remaja merupakan masa transisi yang ditandai oleh perubahan fisik, emosi, dan psikis. Pada ibu berumur kurang dari 20 tahun rahim dan panggul belum tumbuh mencapai ukuran dewasa yang berakibat kemungkinan terjadinya distosia. Penelitian ini bertujuan untuk mendapatkan gambaran persalinan distosia pada remaja di BLU RSUP Prof. Dr. R. D. Kandou Manado periode Januari 2012 - Desember 2013 ditinjau dari umur ibu, paritas, etiologi, tindakan dan komplikasi. Penelitian ini bersifat deskriptif retrospektif. Hasil penelitian memperlihatkan bahwa persalinan distosia pada remaja umumnya terjadi pada usia $>16$ tahun dengan penyebab yang tersering ialah faktor letak, bentuk janin, dan faktor jalan lahir. Tindakan utama yang paling banyak dilakukan yaitu operasi seksio. Distosia jarang menimbulkan komplikasi yang berarti.
\end{abstract}

Kata kunci: persalinan distosia, remaja

Resiko kehamilan pada remaja tidak dapat dipungkiri akan menimbulkan beban fisik tersendiri pada individu yang mengalaminya. Masa remaja merupakan masa pertumbuhan fisik. Jika pada masa ini remaja harus menanggung pertumbuhan lain maka dapat dipasatikan pertumbuhan remaja tersebut baik fisik maupun psikologis akan terhambat. $^{1}$

Distosia adalah persalinan abnormal yang ditandai oleh kemacetan atau tidak adanya kemajuan dalam persalinan atau persalinan yang menyimpang dari persalinan eustasia yang menunjukkan kegagalan. $^{2}$

Remaja (adolescence) berasal dari 
bahasa latin adolescere yang berarti tumbuh kearah kematangan. Kematangan yang dimaksud bukan hanya kematangan fisik saja, tetapi juga kematangan sosial dan psikologis. Menurut BKKBN masa remaja ialah 10-19 tahun. $^{3}$

Pada akhir kehamilan, agar dapat melewati jalan lahir kepala harus dapat mengatasi tebalnya segmen bawah rahim dan servik yang masih belum mengalami dilatasi. Perkembangan otot uterus didaerah fundus uteri dan daya dorong terhadap bagian terendah janin adalah faktor yang mempengaruhi kemajuan persalinan kala I. setelah dilatasi servik lengkap, hubungan mekanis antara ukuran dan posisi kepala janin (fotopelvik proporsi) serta kapasitas panggul dikatakan baik bila desensus janin sudah terjadi akibat regangan uterus berlebihan dan atau partus macet. Dengan demikian maka persalinan yang tidak berlangsung secara efektif adalah merupakan tanda akan adanya fotopelvik disproporsi. ${ }^{2}$

Jika tidak terjadi pola aktivitas uterus yang normal, progresi persalinan akan abnormal (biasanya memanjang). Hingga tahun 1940-an, distosia dianggap disebabkan oleh inersia uteri. Sejak saat itu penelitian menunjukan bahwa beberapa pola aktivitas uterus mungkin menyebabkan kelambatan kelahiran anak. Pola-pola ini disebut aktivitas uterus yang tidak efisien, yang dibagi menjadi aktivitas uterus hipoaktif dan aktivitas uterus hiperaktif yang tidak terkoordinasi. ${ }^{4}$

Ditosia karena kelainan jalan lahir dapat disebabkan adanya kelainan pada jaringan keras/tulang panggul, atau kelainan pada jaringan lunak panggul seperti adanya tumor-tumor. Distosia karena kelainan alat kandungan misalnya atresia vulva (tertutupnya vulva), adanya sekat dan tumor vagina, sikatriks pada serviks karena infeksi atau operasi. ${ }^{5}$

Panggul disebut sempit bila ukurannya 1-2 cm kurang dari ukuran normal. Kesempitan panggul bisa pada inlet (pintu atas panggul), mid pelvis (ruang tengah panggul) atau outlet (dasar panggul). ${ }^{6}$

Dalam keadaan normal, letak janin ialah belakang kepala. Bila janin dalam keadaan malposisi atau malpresentasi, maka dapat terjadi distosia. Malposisi adalah posisi abnormal ubun-ubun kecil relatif terhadap panggul ibu (misalnya posisi oksipito posterior), sedangkan malpresentasi adalah semua letak janin selain letak belakang kepala. Letak janin dapat menyebabkan perpanjangan masa persalinan (misalnya posisi oksipito posterior). Demikian juga besarnya janin. Janin (>4000 gr) tidak mudah dilahirkan pervaginam, meskipun ukuran panggul normal. $^{7}$

Vakum dan forcep kadang kala digunakan pada persalinan normal untuk memudahkan melahirkan. Vakum dan forcep diperlukan ketika janin terganggu atau posisinya tidak normal, ketika wanita tersebut mengalami kesulitan untuk mengejan, atau ketika terjadi distosia. Namun, jika forcep dicoba dan tidak berhasil, operasi sesar dilakukan. ${ }^{8}$

Distosia bahu merupakan kegagalan persalinan bahu setelah kepala lahir dengan mencoba salah satu metode persalinan bahu. Distosia bahu merupakan kegawatdaruratan obstetrik karena terbatasnya waktu persalinan, terjadi trauma janin, dan komplikasi pada ibu. ${ }^{2}$

Persalinan percobaan adalah percobaan untuk persalinan pervaginam pada wanita dengan panggul yang relative sempit. Persalinan percobaan hanya dilakukan pada letak belakang kepala, jadi tidak dilakukan pada letak sunsang, letak dahi, letak muka, atau kelainan letak lainnya. ${ }^{7}$

Percepatan persalinan ialah percepatan buatan pada persalinan yang prosesnya tidak efektif atau terlalu lambat. Oxytocin digunakan untuk percepatan persalinan. ${ }^{8,9}$

Ekstraksi vakum maupun forceps merupakan suatu alat yang dipakai untuk memegang kepala janin yang masih berada dalam jalan lahir. Forcep yang memegang kepala janin dari samping secara teoritis member tenaga pada basis crania janin, sedangkan ekstraksi vakum memegang bagian terdepan dari kepala janin, sehingga dapat dikatakan janin ditarik keluar pada rambutnya. Vakum atau forcep digunakan 
untuk membantu melahirkan. Forcep ditempatkan di sekeliling kepala bayi. Vacuum extractor menggunakan penghisap untuk ditempelkan ke kepala bayi. Dengan alat manapun, bayi ditarik keluar dengan lembut sebagaimana wanita tersebut mengejan. 8,10

Seksio sesarea adalah suatu cara melahirkan janin dengan membuat sayatan pada dinding uterus melalui dinding depan perut atau vagina; atau seksio sesarea adalah suatu histerotomia untuk melahirkan untuk melahirkan janin dari dalam rahim. Operasi seksio bisa dilakukan apabila mengalami kegagalan dalam melakukan persalinan percobaan maupun ektraksi vakum atau forceps. ${ }^{8,9}$

Dampak pada ibu dapat terjadi infeksi intrapartum, ruptur uterus, cedera dasar panggul, fistula post partum. ${ }^{11,7}$ Dampak pada janin dapat terjadi kaput suksedaneum, molase kepala janin, pneumonia, cedera/fraktur dan kematian. ${ }^{7,11}$

\section{METODE PENELITIAN}

Penelitian ini di lakukan di Bagian Obstetri Ginekologi BLU RSUP Prof. Dr. R. D. Kandou Manado periode 1 Januari 2012 - 31 Desember 2013.

Jenis penelitian ini deskriptif retrospektif. Populasi penelitian ialah semua pasien remaja yang dirawat di Bagian Obstetri Ginekologi BLU RSUP Prof. Dr. R. D. Kandou Manado periode 1 Januari 2012 - 31 Desember 2013. Kriteria pengambilan sampel dalam penelitian ini adalah semua pasien remaja yang didiagnosis dengan atau tanpa penyakit penyerta.

\section{HASIL PENELITIAN}

Berdasarkan data pada tabel 1 ditemukan bahwa persentase kasus distosia remaja tertinggi ditemukan pada tahun 2013 sebesar 7 kasus dari total persalinan pada tahun 5140 yaitu $0,13 \%$.

Tabel 2 memperlihatkan bahwa kasus distosia paling banyak ditemukan pada kelompok remaja umur 16-19 tahun yaitu sebesar $100 \%$.
Tabel 1. Distribusi Pasien Distosia Remaja setiap tahun di BLU RSUP Prof. Dr. R. D. Kandou Manado Periode 1 Januari 2012 - 31 Desember 2013

\begin{tabular}{cccc}
\hline Tahun & $\begin{array}{c}\text { Distosia } \\
\text { remaja }\end{array}$ & $\begin{array}{c}\text { Total } \\
\text { persalinan }\end{array}$ & $\%$ \\
\hline 2012 & 5 & 4347 & 0,11 \\
2013 & 7 & 5140 & 0,13 \\
Total & 12 & 9487 & 0,24 \\
\hline
\end{tabular}

Tabel 2. Distribusi Pasien Distosia Menurut Kelompok Umur Remaja di BLU RSU Prof. Dr. R. D. Kandou Manado Periode 1 Januari 2012 - 31 Desember 2013

\begin{tabular}{ccc}
\hline Umur & $\mathrm{n}$ & $\%$ \\
\hline $13-15$ tahun & - & - \\
16-19 tahun & 12 & 100 \\
Total & 12 & 100 \\
\hline
\end{tabular}

Pada tabel 3 ditemukan bahwa pada pasien distosia dengan paritas 0 , memiliki insiden paling tinggi (50\%).

Tabel 3. Distribusi Pasien Distosia pada Remaja Menurut Paritas di BLU RSU Prof. Dr. R. D. Kandou Manado Periode 1 Januari 2012 31 Desember 2013

\begin{tabular}{ccc}
\hline Paritas & $\mathrm{n}$ & $\%$ \\
\hline 0 & 6 & 50 \\
1 & 4 & 33,33 \\
2 & 2 & 16.67 \\
Total & 12 & 100 \\
\hline
\end{tabular}

Berdasarkan data pada tabel 4 ditemukan bahwa distosia remaja paling banyak disebabkan karena masalah letak dan bentuk (passanger) (58,33\%).

Tabel 4. Distribusi Pasien Distosia pada Remaja Menurut Etiologi di BLU RSU Prof. Dr. R. D. Kandou Manado Periode 1 Januari 2012 - 31 Desember 2013

\begin{tabular}{ccc}
\hline Etiologi & $\mathrm{n}$ & $\%$ \\
\hline Power & 2 & 16,67 \\
Passanger & 7 & 58,33 \\
Passage & 3 & 25 \\
Total & 12 & 100 \\
\hline
\end{tabular}


Pada tabel 5 ditemukan tindakan utama yang paling banyak dilakukan pada kasus distosia yaitu operasi seksio $(66,67 \%)$.

Tabel 5. Distribusi Pasien Distosia pada Remaja Menurut Tindakan yang dilakukan di BLU RSU Prof. Dr. R. D. Kandou Manado Periode 1 Januari 2012 - 31 Desember 2013

\begin{tabular}{ccc}
\hline Tindakan & $\mathrm{n}$ & $\%$ \\
\hline Partus spontan : & & \\
Ekstraksi forcep & 3 & 25 \\
Ekstraksi vakum & 1 & 8,33 \\
Abdominal & & \\
Operasi seksio & 8 & 66,67 \\
Total & 12 & 100 \\
\hline
\end{tabular}

Pada tabel 6 ditemukan bahwa pada distosia paling banyak tidak ditemukan komplikasi yaitu sebesar $100 \%$.

Tabel 6. Distribusi Pasien Distosia pada Remaja Menurut Komplikasi Penanganan di BLU RSU Prof. Dr. R. D. Kandou Manado Periode 1 Januari 2012-31 Desember 2013

\begin{tabular}{ccc}
\hline Komplikasi & $\mathrm{n}$ & $\%$ \\
\hline Tanpa komplikasi & 12 & 100 \\
Total & 12 & 100 \\
\hline
\end{tabular}

\section{BAHASAN}

Di bagian rekam medis di BLU RSUP Prof. Dr. R. D. Kandou Manado ditemukan pasien remaja yang didiagnosis distosia pada periode 1 Januari 2012 sampai 31 Desember 2013 di bagian Obstetri Ginekologi RSUP Prof. Dr. R. D. Kandou Manado tercatat sebanyak 12 kasus.

Pada tabel 1 ditemukan tahun 2012 persalinan distosia pada remaja sebanyak 5 kasus $(0,11 \%)$ dari total persalinan 4347. Pada tahun 2013 ditemukan persalinan distosia pada remaja sebanyak 7 kasus $(0,13 \%)$ dari total persalinan 5140 . Total persalinan distosia tahun 2012-2013 sebanyak 12 kasus (0,44\%).

Berdasarkan tabel 2 ditemukan bahwa kasus distosia pada remaja di BLU RSUP
Prof. Dr. R. D. Kandou Manado pada periode 1 Januari 2012 sampai 31 Desember 2013 paling banyak ditemukan pada kelompok remaja umur 16-19 tahun sebanyak 12 kasus (100 \%) dan pada kelompok remaja umur 13-15 tahun tidak ditemukan kasus distosia pada remaja. Hal ini sesuai dengan kepustakaan yang menyatakan bahwa, kehamilan pada remaja akan banyak memiliki resiko pada saat bersalin misalnya partus macet atau distosia. ${ }^{1}$

Berdasarkan tabel 3 ditemukan bahwa insiden distosia pada remaja paling banyak ditemukan pada paritas 0 , yaitu sebanyak 6 kasus (50\%), sedangkan paritas $\geq 3$ tidak ditemukan kasus distosia remaja. Hal ini sesuai dengan kepustakaan yang menyatakan bahwa wanita nulipara berisiko sebesar 5-6 kali untuk terjadi kemacetan dalam persalinan.

Berdasarkan tabel 4 ditemukan bahwa distosia pada remaja yang paling banyak disebakan oleh faktor passenger yaitu sebanyak 7 kasus (58,33\%) dan faktor passage yaitu sebanyak 3 kasus (25\%). Sedangkan faktor power yaitu sebanyak 2 kasus (16,67\%). Dalam penelitian yang dilakukan faktor passenger yang ditemukan yaitu bayi makrosomia. Hal ini sesuai dengan kepustakaan yang menyatakan bahwa pada saat bersalin misalnya, remaja akan banyak memiliki resiko partus macet atau distosia karena ukuran panggul ibu yang masih remaja lebih kecil daripada bayi yang sedang dilahirkannya. ${ }^{1}$

Pada tabel 5 ditemukan bahwa tindakan utama yang dilakukan untuk kasus ditosia pada remaja yaitu operasi seksio yaitu sebanyak 8 kasus $(66,67 \%){ }^{5}$

Pada tabel 6 ditemukan bahwa luaran ibu dengan persalinna distosia paling banyak tanpa disertai kompilkasi yaitu sebanyak 12 kasus (100\%). Hal ini tidak sesuai dengan kepustakaan yang menyatakan bila partus macet, resiko ruptur sedangkan untuk komplikasi ruptur uteri yang timbul adalah dikarenakan oleh tindakan yang dilakukan untuk mengatasi distosia yang dialami ibu saat bersalin. Untuk komplikasi lain seperti fistula post 
partum dan infeksi intrapartum tidak ditemukan dalam kasus. ${ }^{7,11}$

\section{SIMPULAN}

Persalinan distosia pada remaja umumnya terjadi pada usia $>16$ tahun, dengan penyebab yang paling sering Ialah faktor letak dan bentuk janin, serta faktor jalan lahir. Tindakan utama yang paling banyak dilakukan pada distosia yaitu operasi seksio setelah persalinan percobaan kemudian gagal.

Distosia jarang menimbulkan komplikasi yang berarti, oleh karena itu hasil akhir dari pasien dengan distosia sangat baik.

\section{SARAN}

Untuk para remaja, dianjurkan lebih mempertimbangkan usia untuk hamil serta mempersiapkan mental dan fisik ketika hamil mengingat kehamilan pada usia remaja memiliki banyak risiko.

Perlu adanya manajemen data agar pengambilan data dapat lebih teratur dan terfokus sehingga proses pengambilan data menjadi lebih akurat.

\section{DAFTAR PUSTAKA}

1. Emilia O, Freitag H. Tetap Bugar dan Energik Selama Hamil. Jakarta: Agro Media, 2010; p. 163.
2. Josep HK, Nugroho MS. Catatan Kuliah Obstetri dan Ginekologi (Obsgyn). Jakarta: Nuha Medika, 2011; p. 247-8.

3. Widyastuti $Y, \quad$ Rahmawati A, Purnamaningrum YE. Kesehatan Reproduksi (Cetakan kedua). Yogyakarta: Penerbit Fitramaya, 2009; p. 10-12.

4. Llwellyn DJ. Dasar-Dasar Obstetri Ginekologi (Ed. 6). Jakarta: Hipokrates, 2001; p. 163-6.

5. SMF Ginekologi FK Unpad Bandung. Obstetri Patologi. Bandung: Elstar Offset, 1984; p. 216-7.

6. Mochtar R. Sinopsis Obstetri Fisiologi Jilid I (Ed. II). Jakarta: EGC, 1998.

7. Sastrawinata S, Wirakusumah MA. Ilmu Kesehatan Reproduksi: Obstetri Patologi (Ed. 2). Jakarta: EGC, 2004; p. 121.

8. Achadiat CM. Prosedur Tetap Obstetri dan Ginekologi. Jakarta: EGC, 2004; p. 70.

9. Simkin P, Ancheta R. Buku Saku Persalinan terjemahan. Jakarta: EGC, 2005.

10. Cunningham FG, Gant NF, et al. Obstetri Williams (Ed. 21). Jakarta: EGC, 2005; p. 487-90.

11. Prawirohardjo S, et al. Ilmu Kebidanan (Ed. 4). Jakarta: PT Bina Pustaka, 2009; p. 562, 567-9. 